\title{
Participation in heritage crowdsourcing
}

\section{Accepted version; pre-print manuscript for Museum Management and Curatorship.}

Chiara Bonacchi, Andrew Bevan, Adi Keinan-Schoonbart, Daniel Pett, Jennifer Wexler

\section{Introduction}

\subsection{Research problem}

Studies of cultural participation in the UK today show that certain social demographics remain very detached from museums and galleries (Bennet et al., 2009). Given that such places have long been powerful but problematic symbols of western culture, ever since their first emergence during the Renaissance, it remains striking that both museums and galleries have, on the whole, failed to engage ethnic minorities and people in lower socio-economic groups (Sandell, 2002). For example, despite policies to ensure free entrance to statefunded museums, variables such as high socio-economic background, a university degree and/or a professional occupation have, together with ethnicity, all remained good predictors of high levels of participation in cultural activities (Neelands et al., 2015). Similar trends have been noted in the United States, where the attendance of financially disadvantaged groups and minorities at public art museums has been declining, despite the fact that US society overall is increasingly multicultural and ethnically diverse (Blackwood and Purcell, 2014). These UK and US findings are also consistent with results obtained by previous surveys worldwide (DiMaggio et al., 1979; Merriman, 1989; National Endowment for the Arts, 1997; Selwood, 2002; La Regina, 2009; Taylor, 2016), with cultural factors proving stronger than structural ones in determining disengagement (Merriman, 1989). Indeed, commentators have stressed that part of the problem of representation in cultural participation relates to the fact that what is being measured is typically footfall at state-funded venues (Stevenson et al., 2015:100-1). In contrast, some argue that, if policies were developed to better support and monitor everyday cultural activities (e.g. woodworking, DIY, gardening, etc.), these would directly benefit more people beyond well-off, white individuals with tertiary education. Furthermore, re-thinking the ways in which policies are designed, implemented and evaluated would help in actualising cultural democracy in a more convincing way (Taylor, 2016; Hadley and Belfiore, 2018).

Bennet et al. (2009) explain under-representation of certain groups at museums, galleries and stately homes as also linked to the fact that these are forms of active public 
participation, which studies of social capital have consistently shown to be less common amongst lower socio-economic groups (e.g. Hall, 1999; Li et al., 2003; Warde et al., 2003). In this article, we ask what happens when engagement with museum, gallery, and archive content and materials is instead conducted in the private space of the home or the office, thanks to the application of crowdsourcing. Does this make participation more diverse or does the important social problem of selective under-representation persist?

\subsection{Research context: heritage crowdsourcing}

Crowdsourcing was a term first coined by Jeff Howe in a seminal article for Wired magazine (Howe, 2006) by combining the words 'crowd' and 'outsourcing' in order to refer to the commercial practice of distributing paid labour amongst individuals located in geographically disparate regions of the globe. Outside of the commercial world, however, the meaning and mission of this practice have changed to adapt to the remit of not-for-profit activities. In most cases, this has entailed not offering monetary rewards in exchange for the completion of crowdsourced tasks (Ridge, 2013), with user motivations instead often being primarily intrinsic. For the purpose of this article, we will define heritage crowdsourcing as the creation, digitisation, enhancement, analysis and interpretation of cultural heritage objects (including data) and places by relatively large groups of people, through the completion of individually small tasks over the Internet.

In the last decade, crowdsourcing has been increasingly explored by higher education institutions, Galleries, Libraries, Museums and Archives (GLAMs) and heritage organisations (Dunn and Hedges, 2012; Ridge, 2013, 2014; Terras, 2016). Some of these crowdsourcing undertakings have been set up by a specific institution as standalone endeavours or as a series of projects relating to the collections held by that institution. This is the case for several initiatives led by GLAMs such as the British Library, the New York Public Library, the National Library of Australia, or the Smithsonian Transcription Centre, and by a few singlepurpose research endeavours such as Field Expedition: Mongolia and GlobalXplorer (Holley, 2010; Lascarides and Vershbow, 2014; Lin et al., 2014; Parilla and Ferriter, 2016; Ridge, 2018; Yates, 2018). A second group of projects has instead been hosted by thematically focused or multi-topic crowdsourcing websites, as in the case of Zooniverse or MicroPasts (Lintott et al., 2008; Bevan et al., 2014). These platforms have created an array of crowdsourcing templates to perform tasks of different kinds, ranging from the transcription of archival documents to the public indexing of photographs and videos through social tagging. They have also become spaces that bring together different institutions, cultural heritage objects and task types. It is with this second category that our article is concerned, via the case study of MicroPasts (see 2.). 
In the next section, we introduce MicroPasts, which is to our knowledge the first website hosting multiple types of heritage crowdsourcing, and we explain how this project has helped to create a distributed and primarily 'private' kind of cultural participation. MicroPasts placed a considerable, publicly-acknowledged emphasis on evaluating participant profiles, motivations and behaviour and a following section examines how the socio-demographic dimensions of MicroPasts participants compare to those of people who take part in statefunded heritage activities via physical visitation; it explores what the democratising power of heritage crowdsourcing could be, and how this method can help museums, galleries and other state-funded institutions to diversify participation.

\section{Methodology}

\subsection{MicroPasts: a case study of heritage crowdsourcing}

MicroPasts was established in 2013 by a team of researchers at the UCL Institute of Archaeology and the British Museum (with coordination also now provided by researchers at the University of Cambridge Fitzwilliam Museum and the University of Stirling), thanks to funding from the UK Arts and Humanities Research Council (Bevan et al., 2014; Bonacchi et al., 2014, 2015a, 2015b; Wexler et al., 2015). Its aim has been to leverage crowd- and other web-based methods to create and study collaborations between citizens inside and outside heritage organisations, in order to co-produce data and knowledge about the human past and its contemporary reception. The MicroPasts crowdsourcing website (crowdsourced.micropasts.org) has been developed using Free and Open Source Software and particularly an existing citizen science framework known as Pybossa (Scifabric, 2018), which supports sophisticated task scheduling, a registered user base and a wide variety of different applications. Sometimes building on existing Pybossa templates, sometimes creating new ones, MicroPasts has developed a series of modular applications each tuned to enable collective capture of a specific kind of open data (e.g. 3D models, transcriptions, photo tags), and this modularity enables easy adaptation to different archaeological and heritage collections. Task redundancy and a mix of automatic and expert quality assessment have been the main mechanisms used to ensure that the resulting crowdsourced data is of good research quality (Allahbakhsh et al., 2013; Daniel et al., 2018). This means that each crowdsourcing task (e.g. transcription, tagging, etc.) is completed by two or more participants, depending on the application template, and is subsequently consolidated by an experienced participant and/or a 'traditional' researcher. Raw, crowdsourced and verified 
data is released (immediately, as it is produced) via the website under a Creative Commons license (primarily as CC-BY) and the source code under a General Public License.

Until now, the majority of the crowdsourcing applications powered by MicroPasts consisted of transcription and 3D photo-masking, and, in the first two years, they focused especially on Bronze Age museum collections. During this initial phase, the project transcribed and georeferenced the National Bronze Age Index, an archive of about 30,000 cards documenting prehistoric metal artefacts found in Britain during the $19^{\text {th }}$ and early $20^{\text {th }}$ century (Pett et al., 2014; Wexler et al., 2015; Figure 1). Participants online were also invited to help with drawing outlines of objects on sets of photos of those objects to mask out the background (Lombraña González et al., 2014; Figure 2). This task was designed to facilitate and speed-up the 3D modelling of artefacts via photogrammetric approaches that otherwise proceeded offline (Bevan et al., 2014). Over time, MicroPasts has also enabled quite different applications often on a more one-off experimental basis, such as those for the public indexing of historical photographs, the testing of object description vocabularies via tagging (e.g. Keinan-Schoonbaert et al., 2014), content analysis through video-tagging or sound track transcription, while also adapting and using existing transcription templates for the digitisation of structured and unstructured textual data. This varied crowdsourcing landscape has been nurtured through collaborations with 20 other museums, archives, libraries, heritage groups and university-led research projects in the UK, US, Italy and Germany (Table 1).

Figure 1. Screenshot showing the functioning of the transcription and geo-referencing application used to crowdsource the digitisation of the National Bronze Age Index.

Figure 2. Screenshot showing the functioning of the 3D photo-masking application.

Table 1. Organisations involved with MicroPasts beyond the founding institutions (UCL and the British Museum).

\begin{tabular}{|l|l|}
\hline $\begin{array}{l}\text { Country where the } \\
\text { institution/project } \\
\text { lead is based }\end{array}$ & Organisations and projects \\
\hline \multirow{4}{*}{ UK } & Petrie Museum \\
\cline { 2 - 2 } & Ancient Identities in Modern Britain project \\
\cline { 2 - 2 } & Society of Antiquaries of London \\
\cline { 2 - 2 } & New Forest National Park Authority \\
\cline { 2 - 2 } & Portable Antiquities Scheme \\
\cline { 2 - 2 } & Egypt's Exploration Society \\
\cline { 2 - 2 } & Postcard to Palmyra project \\
\hline
\end{tabular}




\begin{tabular}{|l|l|}
\hline \multirow{4}{*}{} & Archaeology Data Service \\
\cline { 2 - 2 } & Sainsbury Institute for the Study of Japanese Arts and Cultures \\
\cline { 2 - 2 } & The Impact of Evolving Rice Systems from China to Southeast Asia \\
\cline { 2 - 2 } & Mary Rose Trust \\
\cline { 2 - 2 } & Palestine Exploration Fund \\
\hline \multirow{4}{*}{ US } & Montpellier Foundation \\
\cline { 2 - 2 } & Project Andvari \\
\cline { 2 - 2 } & American Numismatic Society \\
\cline { 2 - 2 } & Minnesota Historical Society \\
\cline { 2 - 2 } & Denver Museum of Nature and Science \\
\hline Germany & Museo Egizio \\
\cline { 2 - 2 } & Museo Multimediale del Regno di Arborea \\
\hline
\end{tabular}

Although MicroPasts started by enabling a strongly scaffolded and contributory kind of participation, where people were invited to complete rather mechanical crowdsourcing tasks (e.g. for transcription, geo-referencing, photo-masking and tagging, etc.), it thereafter evolved to encompass collaborative and co-creative levels of participation as well (Simon, 2010). So far, MicroPasts has mainly enabled projects designed by museums, archives and teams of academic researchers, but, over the years, citizen collaborators have been encouraged to suggest ways of taking forward the MicroPasts project and platforms and of improving workflows and procedures. As a result, some of the volunteers also started to undertake new activities they had proposed and which required additional skills and deeper engagement at the interface between the generation and interpretation of cultural heritage data. In particular, a small group of eleven participants learnt the full online and offline pipeline to build 3D models, while half a dozen people (in some cases coinciding with the first group of 3D modellers) also helped validate transcribed entries before these were finally approved by a researcher based in the relevant partner organisation. In this paper, however, we will examine only the contributory level of participation consisting in the submission of crowdsourcing tasks, given the small number of those involved in collaborative and cocreative efforts.

\subsection{Evaluation and research methods}

As heritage crowdsourcing initiatives have emerged, researchers have tried to better understand their users and the interests and values behind their participation. This body of research, primarily grounded in individual project evaluations, has, however, been conducted mainly via end-of-project surveys or cross-sectional formative investigations (Holley, 2010; Causer and Wallace, 2012; Causer and Terras, 2014; Ridge, 2014). To our knowledge, heritage crowdsourcing has never been evaluated longitudinally with a view to understanding participant profiles, motivations and behaviour, as well as the scope, potential and limitations of participant representation. 
With the latter goals in mind, and adopting a longitudinal, mixed quantitative and qualitative approach, MicroPasts collected behavioural data from the records of completed tasks, as well as socio-demographic and attitudinal information from pop-up surveys that were coded to appear, respectively, after the submission of the $1^{\text {st }}$ and of the $25^{\text {th }}$ crowdsourcing task. The results from the short survey undertaken after the first task cover: (1) how the contributor found out about MicroPasts; and (2) whether he/she was working with archaeology or history as part of his/her main job (the main job done for living). The second survey, appearing after the submission of the $25^{\text {th }}$ crowdsourcing task aimed to question more heavily-engaged participants who had been involved with MicroPasts far beyond a single, first encounter. The threshold of twenty-five was decided after evaluating the possible cut-off points in plots that displayed the ranking of participants based on their number of completed tasks, as recorded two months after the public launch of the crowdsourcing platform (see Bonacchi et al., 2014). ${ }^{1}$ The results of this second survey cover: (1) the contributor's reasons for participating in the specific crowdsourcing application to which the survey was linked, and (2) any other crowdsourcing applications the participant might have been involved in; (3) the highest level of formal education attained; (4-5) the participant's occupation and, if in employment, job title; and (6) the country where the contributor was living (see Appendix 1 for the full questionnaires). Obviously, the above choices about the number of surveys and the depth of their questioning reflect a balancing act in terms of asking yet more of people already volunteering their time online, and in particular we judged that it might be potentially off-putting and disruptive to inquire about ethnicity or income, and decided not to include questions on these measures.

Social survey literature (Bryman, 2012) suggested to us that questioning participants while they were still connected to the platform, rather than at the end of the whole project, would increase the reliability of answers to questions about their interaction with the applications, the overall response rate, the response rate to open-ended questions and the richness of the responses to those questions. As previously mentioned, prior evaluations of heritage crowdsourcing based on social surveys were cross-sectional and, as such, allowed for the gathering only relatively small numbers of responses. Over the period from 16 April 2014 to 27 April 2017, during which the evaluation took place, it was possible to collect 853 task-1 survey responses and 56 task-25 survey responses.

\footnotetext{
${ }^{1}$ At the time when the decision was made, the median of crowdsourcing tasks submitted oscillated between two and five tasks across the applications available at the time (Bonacchi et al., 2015b).
} 


\section{Results}

\subsection{Participant representation}

MicroPasts' outreach efforts were aimed at two main groups of people, consisting of communities of interest in the past that were already established offline (e.g. archaeological and historical societies in Britain, the metal detectorists working with the Portable Antiquities Scheme, existing British Museum audiences, students and academics at UCL and at other universities), and a wider and unknown online 'crowd' of geographically dispersed collaborators. The outreach campaign was undertaken through social media, blogs, online magazines and newspapers, as well as more targeted emails and few face-to-face presentations to selected groups. As already noted by other crowdsourcing projects, online publicity was more effective in attracting a higher number of contributors than any other kind of tailored communication (Causer and Wallace, 2012).

Table 2. How participants had heard of MicroPasts.

\begin{tabular}{|l|l|}
\hline How they heard of MicroPasts & Count \\
\hline $\begin{array}{l}\text { Via British Museum people/websites/social } \\
\text { media and/or Portable Antiquities Scheme }\end{array}$ & 166 \\
\hline $\begin{array}{l}\text { Via UCL people/websites/social media and/or } \\
\text { Portable Antiquities Scheme }\end{array}$ & 49 \\
\hline $\begin{array}{l}\text { Via people/websites of another university (NOT } \\
\text { University College London) }\end{array}$ & 39 \\
\hline $\begin{array}{l}\text { I was told by someone who does NOT belong to } \\
\text { any of the categories listed above }\end{array}$ & 55 \\
\hline Casually browsing the web & 115 \\
\hline From an online newspaper/magazine & 145 \\
\hline Via an archaeological/historical society & 45 \\
\hline
\end{tabular}

As a result of this outreach, 1623 people registered with MicroPasts, but not necessarily active on it, up until 30 April 2017, in addition to anonymous collaborators whose numbers we cannot estimate with complete accuracy, but are likely, based on IP addresses, to be considerably larger than the registered group. Visits to the MicroPasts website have been widespread internationally, but the number of those from the UK and US has been the highest (Figure 3). Only a minority of individuals had heard of MicroPasts directly from the founding institutions (the British Museum or the UCL Institute of Archaeology) and because they were already engaged with them; the majority instead came to know of MicroPasts by casually browsing the web and/or via online newspapers such as the Guardian, magazines such as British Archaeology and Discovery, heritage or technology blogs and news sites 
(e.g. hyperallergic.com, popsci.com, etc., Table 2). More engaged participants had attained relatively high levels of formal education, with almost all of them having either a university degree or a post-graduate degree (21 in each category, out of 49 respondents to this question in the task-25 survey). Furthermore, the large majority of more engaged contributors was either in employment or retired and these two groups together made up $88 \%$ of the total of task-25 survey respondents, with the remaining $21 \%$ being composed of students, unemployed or stay-at-home participants. These findings are in line with the results of cross-sectional evaluations of other heritage crowdsourcing projects (Causer and Wallace, 2012; Eccles and Greg, 2014).

Not only did a large part of contributors consist of professionals, but the latter held jobs that frequently were related in some way to the activities and the tasks proposed. Three quarters of respondents to the task-1 survey $(72 \%)$ were not working with history or archaeology as part of their main job they did for living (Figure 4). However, based on the job titles mentioned by task-25 survey respondents, we know that many of the more engaged participants were active in fields that spanned administration, database management, accountancy, sales, transports, communication, publishing, IT, and sometimes the arts and humanities.

Figure 3. (a) Screenshot from Google Analytics showing the geographic spread of visits to the MicroPasts website; (b) top ten countries from which sessions originate.

Figure 4. MicroPasts participants' relevance of their main job to the fields of archaeology or history. Break-down of task-1 survey respondents.

\subsection{The centrality of process and activity type}

As of 30 April 2017, 1009 registered participants had been actively involved at contributory level on the MicroPasts crowdsourcing platform and a further group of anonymous users that we estimate (from IP address uniqueness) to be considerably higher than the number of registered ones. In line with the findings presented in other published literature, the distribution of this kind of participation exhibited a long tail, with a very small group of people submitting the vast majority of the tasks and a high number of more fleetingly involved participants (Figure 5, which confirms the trend already discussed in Bonacchi et al., 2014 and in Holley, 2010; Oomen and Aroyo, 2011; Corneli and Mikroyannidis, 2012: 284; Dunn and Hedges, 2012: 12; Causer and Terras, 2014; Eccles and Greg, 2014). The trend can be observed for participation in transcription and photo-masking applications without marked differences, as proved by the similarities in Gini coefficient for these two crowdsourcing task 
types (Figure 6). Gini coefficient and Lorenz curve are measures of inequality, frequently applied in the social sciences and especially in economics (e.g. Fidan, 2016; Brown, 2017); here we use the Gini coefficient, which is the ratio of the area that lies between the line of equality ( $45^{\circ}$ line in Figure 4$)$ and the Lorenz curve (the red curve in Figure 4): a metric where 1 expresses maximum inequality and 0 minimum inequality.

The number of participants engaged in transcription and photo-masking, the two crowdsourcing application types that were deployed since the beginning of MicroPasts, are not significantly different (Table 3). However, participants mostly tended to engage with either one or the other kind of task, and only $18 \%$ of them engaged with both types of crowdsourcing activities (Table 4). This is particularly significant if we consider that, for the first two years of the project both transcription and 3D photo-masking tasks focused mostly on the same collections, consisting of Bronze Age metal artefacts housed at the British Museum and their object cards. The type of material that people engaged with, instead, had less of an impact on the choice of the applications to participate in (Table 5).

Figure 5. Rank size plot for both photo-masking and transcription tasks as of 30 April 2017.

Figure 6. Lorenz curve (red) and Gini coefficient for photo-masking tasks (left) and transcription tasks (right), calculated on tasks submitted as of 30 April 2017.

Table 3. Participants engaged with each crowdsourcing task type. ${ }^{2}$

\begin{tabular}{|l|l|l|}
\hline Task type & Count & $\%$ \\
\hline Participants engaged in photo-masking & 511 & 50.6 \\
\hline Participants engaged in transcription & 642 & 63.6 \\
\hline Participants engaged in tagging/classification & 115 & 11.4 \\
\hline
\end{tabular}

Table 4. Participants engaged with 1-3 different task types.

\begin{tabular}{|l|l|l|}
\hline & Count & $\%$ \\
\hline Participants who did only one type of task & 795 & 79 \\
\hline Participants who did 2 types of task & 182 & 18 \\
\hline Participants who did all 3 types of task & 32 & 0.03 \\
\hline
\end{tabular}

Table 5. Participants engaged with different types of heritage assets: text-based or visual and audio-visual assets.

\footnotetext{
${ }^{2}$ It should be noted that, as underlined before, photo-masking and transcription are the crowdsourcing types of applications that were deployed more consistently and substantially since the public launch of the MicroPasts project.
} 


\begin{tabular}{|l|l|l|}
\hline & Count & $\%$ \\
\hline Participants engaged with text-based applications only & 415 & 41 \\
\hline Participants engaged with visuals-based applications only & 339 & 34 \\
\hline Participants engaged with both text-based and visuals-based applications & 248 & 25 \\
\hline
\end{tabular}

The insights provided by behavioural data regarding the centrality of activity type to the appeal of crowdsourcing are reinforced by the qualitative analysis of participants' motivations. Responses to the task-25 survey were examined with the aim of identifying the smallest possible number of different motivational categories, of which eight stood out (Table 6). Certain very intrinsic kinds of motivation are prevalent (a general sense of helping out, the sheer enjoyment of the experience, the act of giving back to an institution, etc.), proving that process underlies several of the main reasons why people participate in heritage crowdsourcing. Enjoying the proposed activity, contributing to knowledge production, and 'helping out' are all process-focused motivations. By comparison, a desire to engage with a particular kind of heritage object or subject does not feature prominently, if at all. This result is interesting in that it corroborates findings from the previous section, regarding a possible link between activity types and contributors' professions. ${ }^{3}$

Table 6. Participant motivations, analysed from the responses given to the task-25 survey.

\begin{tabular}{|l|l|}
\hline Motivational category & Examples \\
\hline Learning about history and archaeology & $\begin{array}{l}\text { An interesting way to learn a bit more about } \\
\text { history \& archaeology. }\end{array}$ \\
\cline { 2 - 2 } & $\begin{array}{l}{[\ldots] \text { I am learning a little bit about archaeology in }} \\
\text { the process. }\end{array}$ \\
\hline Giving back to / connecting with an institution & $\begin{array}{l}\text { Assisting the British museum as a thank you for } \\
\text { visiting out metal detecting club (Trowbridge) }\end{array}$ \\
\cline { 2 - 2 } & $\begin{array}{l}\text { Volunteering in return for help/support received } \\
\text { from the FLO for Birmingham and Staffs. }\end{array}$ \\
\hline Interest and curiosity & A basic fascination with history \\
\cline { 2 - 2 } & curiosity \\
\cline { 2 - 2 } & $\begin{array}{l}\text { I am a Celtic Artist with a degree in } \\
\text { Anthropology, and I find the work interesting. }\end{array}$ \\
\hline Skill building or career development & $\begin{array}{l}\text { Experience for a future career in Ancient History } \\
\text { and Archaeology, as I am currently studying a } \\
\text { part-time BA (Hons) degree in Classical } \\
\text { Studies. I am also between modules at the } \\
\text { moment, so I have the time to dedicate to this } \\
\text { project. }\end{array}$ \\
\hline Enjoyment & Find this fascinating, addicted and worthwhile \\
\cline { 2 - 2 } & Fun \\
\hline
\end{tabular}

\footnotetext{
${ }^{3}$ In future and pending the availability of a sufficient number of responses to support the assessment of statistically significant relationships, it would also be helpful to investigate possible links between motivations for participating, on the one hand, and contributors' occupation, profession and location on the other.
} 


\begin{tabular}{|l|l|}
\hline \multirow{2}{*}{ Helping out } & $\begin{array}{l}\text { I enjoy it. I am learning a little bit about } \\
\text { archaeology in the process. }\end{array}$ \\
\cline { 2 - 2 } & It's oddly relaxing \\
\hline Contributing to knowledge production & Helping a project \\
\cline { 2 - 2 } & {$[\ldots]$ I am happy to help with the projects } \\
& I just want to help. \\
\hline & $\begin{array}{l}\text { I have been interested in archaeology since I } \\
\text { was a child. This is a chance for me to } \\
\text { participate in increasing the availability of } \\
\text { knowledge for scholars. I was also a fan of } \\
\text { "Time Team"! }\end{array}$ \\
\cline { 2 - 2 } & $\begin{array}{l}\text { To help contribute towards greater scientific } \\
\text { knowledge }\end{array}$ \\
\cline { 2 - 2 } & {$[\ldots]$ help out with the historical research } \\
\hline Identity and self-definition & $\begin{array}{l}\text { Ancestors were English and Scottish (and } \\
\text { American Indian). }\end{array}$ \\
\hline
\end{tabular}

\section{Discussion}

The analysis has, we would argue, demonstrated that crowdsourcing is often a highly process-focused activity. It is primarily the kind of activity - transcription, photo-masking or tagging and classification, for example - that affects what crowdsourcing applications people decide to engage with. Participants tend to choose a specific activity type consistently and there is some limited but thought-provoking evidence to suggest a link between a contributor's profession and their preferred type of crowdsourcing, even if more research and analysis is clearly needed to confirm or falsify this latter hypothesis. Conversely, a desire to connect with a certain institution or a personal interest in a particular collection or asset type (text, photo, video, sound) are less decisive in determining the kind of crowdsourcing people engage with. In contrast, in his survey-based study of museum visitation, Merriman (1989) showed that a specific or general interest in museum content was the most frequently mentioned motivation for people's physical visitation of museums.

As a process-focused activity that is mostly undertaken on one's own and often at home, we might expect heritage crowdsourcing to appeal to a cohort of participants with similar sociodemographics to individuals engaged in everyday cultural activities such as DIY or crafts. We could then imagine wider representation across the dimensions of education and occupation, but this is not the case. A possible reason is that, in crowdsourcing, social motivations expressed through volunteering or helping out behaviour are at the basis of the engagement, and these recur more amongst those who have higher income and formal education levels (Gil-Lacruz et al., 2017 for a synthesis of studies on the positive correlation between income and education, and volunteerism). In fact, a study by Ponciano and Brasileiro characterises contributors at the peak of the long tail of participation in 
crowdsourcing as volunteers (those submitting the vast majority of the tasks, see section 3.1 above), and the long tail itself of the more fleetingly involved as engaged in 'helping out' behaviour (Ponciano and Brasileiro, 2014). The first of these, volunteerism, characterises people "usually actively seeking out opportunities to help others", whereas the second, 'helping out behaviour', is "sporadic participation in which the individual is faced with an unexpected request to help someone to do something" (Ponciano and Brasileiro, 2014:248). Additionally, using a crowdsourcing web platform requires digital skills, adequate Internet access, software and hardware to participate, and these are also less widespread amongst the more economically vulnerable (Eynon, 2009; Simon, 2010). Whilst all these factors may have a role, how they play out together is something that needs further empirical investigation to be fully understood.

In the light of this study and supporting reflections by others, heritage crowdsourcing cannot necessarily or always be defined as a democratising form of cultural engagement, but it can help GLAMs and heritage places to reach some of those with whom they have not already engaged. It can be of use, for instance, to initiate and sustain participation among people who have neither a general nor a strong interest in the human past, heritage objects or places, but who are very much interested in performing certain types of activities. Thus, more dedicated efforts to publicise heritage crowdsourcing amongst activity-focused groups of interest such as photographers, contributors to other crowdsourcing projects revolving around similar task types, digital DYI communities, 3D modellers etc. would be a promising means by which effectively to expand participation in museum collections and content beyond existing audiences, even though this may still be within a rather homogeneous, welleducated and well-off group of participants. This 'expansion' would not be likely to be quantitatively large either, since active participants (those who do most of the tasks and/or register with named accounts, for example) in heritage crowdsourcing are not 'crowds' (see section 3.1., also Ridge, 2013; Causer and Terras, 2014). Additionally, most of them are involved only occasionally and lightly, leaving just a handful to complete most of the proposed tasks. These numbers could be slightly more significant for smaller organisations, also helping them to acquire visibility as a result of joining an existing, multi-project and multi-institution platform that display stronger brands such as that of the British Museum. The choice to join an existing multi-project platform, rather than setting up an additional and standalone one, is strategic also because such platform offers more of the same types of applications, albeit focussing on different collections.

In conclusion, this research shows the potential of crowdsourcing as a method for participatory heritage creation, enhancing and interpretation that museums, galleries, 
archives and libraries can adopt to involve people whose primary interests do not necessarily relate to GLAMs collections or indeed themes, but are instead strongly linked to the activities that crowdsourcing projects enable. In doing so, the article is the first to focus the actual 'civic', albeit not always socially democratising, role of this web-based collaborative method: it can allow breaking the 'fourth wall' of existing audiences and include some of those who rarely interact with heritage via GLAMs institutions. Our research thus highlights the utility and importance of embedding digitally-enabled cultural participation in museums. Proceeding in this direction will permit to create spaces that are more convincingly integrating private and public, state-funded and everyday forms of participation. Over time, this is likely to help construct systems of heritage curation whose principles, priorities and operations are more widely shared amongst the population and co-designed.

\section{References}

Allahbakhsh, M., Benatallah, B., Ignjatovic, A., Motahari-Nezhad, H. R., Bertino, E., \& Dustdar, S. (2013). Quality Control in Crowdsourcing Systems: Issues and Directions. IEEE Internet Computing, 17(2), 76-81. DOI: 10.1109/MIC.2013.20.

Bennet, T., Savage, M., Silva, E., Warde, A., Gayo-Cal, M., \& Wright, D. (2009). Culture, class distinction. Abingdon and New York: Routledge.

Bevan, A., Pett, D., Bonacchi, C., Keinan-Schoonbaert, A., Lombraña González, D., Sparks, R., Wexler, J., \& Wilkin, N. (2014). Citizen Archaeologists. Online Collaborative Research about the Human Past. Human Computation, 1(2), 185-199. DOI: 10.15346/hc.v1i2.9.

Blackwood, A. \& Purcell, D. (2014). Curating Inequality: The Link between Cultural Reproduction and Race in the Visual Arts. Sociological Inquiry, 84(2), 238-263. DOI: 10.1111/soin.12030.

Bonacchi, C., Bevan, A., Pett, D., Keinan-Schoonbaert, A., Sparks, R., Wexler, J. \& Wilkin, N. (2014). Crowd-sourced Archaeological Research: The MicroPasts Project. Archaeology International, 17. DOI: 61-68. 10.5334/ai.1705.

Bonacchi, C., Pett, D., Bevan, A., \& Keinan-Schoonbaert, A. (2015a). Experiments in Crowdfunding Community Archaeology. Journal of Community Archaeology \& Heritage, 2(3), 184- 
198. DOI: 10.1179/2051819615Z.00000000041.

Bonacchi, C., Bevan, A., Pett, D., \& Keinan-Schoonbaert, A. (2015b). Crowd- and Community-fuelled Archaeology. Early Results from the micropasts Project. In Giligny, F., Djindjian, F., Costa, L., Moscati, P. \& Robert, S. Eds. CAA2014, $21^{\text {st }}$ Century Archaeology. Concepts, Methods and Tools. Proceedings of the $42^{\text {nd }}$ Annual Conference on Computer Applications and Quantitative Methods in Archaeology, Paris. Oxford: Archaeopress, pp. 279-288.

Brown, R. (2017). Inequality crisis. Bristol: Policy Press.

Bryman, A. (2012). Social Research Methods. Oxford: Oxford University Press.

Causer, T. \& Terras, M. (2014). 'Many Hands Make Light Work': Transcribe Bentham and Crowdsourcing Manuscript Collections. In M. Ridge. Crowdsourcing Our Cultural Heritage. Farnham: Ashgate Publishing Limited, pp. 57-88.

Causer, T. \& Wallace, V. (2012). Building A Volunteer Community: Results and Findings from Transcribe Bentham. DHQ: Digital Humanities Quarterly, 6(2).

http://www.digitalhumanities.org/dhq/vol/6/2/000125/000125.html (accessed 23 August 2018).

Corneli, J. \& Mikroyannidis, A. (2012). Crowdsourcing Education on the Web: A Role-Based Analysis of Online Learning Communities. In: Okada, A., Connolly, T., Scott, P.J. (Eds.) Collaborative Learning 2.0: Open Educational Resources. IGI Global. DOI: 10.4018/978-14666-0300-4.

Daniel, F., Kucherbaev, P., Cappiello, C., Benatallah, B. \& Allahbakhsh, M. (2018). Quality Control in Crowdsourcing: A Survey of Quality Attributes, Assessment Techniques, and Assurance Actions. ACM Computing Surveys, 51, 1-40. DOI: 10.1145/3148148.

DiMaggio, P., Useem, M. \& Brown, P. (1979). Audience Studies of the Performing Arts and Museums: A Critical Review. Washington, DC: National Endowment for the Arts, Research Division, Report 9. https://www.arts.gov/publications/audience-studies-performing-arts-andmuseums-critical-review (accessed 23 August 2018). 
Dunn, S. \& Hedges, M. (2012). Crowd-Sourcing Scoping Study. Engaging the Crowd with Humanity Research. London: Centre for e-Research, Department of Digital Humanities, King's College London. https://www.nottingham.ac.uk/digital-humanitiescentre/documents/dunn-and-hedges-crowdsourcing.pdf (accessed 17 September 2017).

Eccles, K. \& Greg, A. (2014). Your Paintings Tagger: Crowdsourcing Descriptive Metadata for a National Virtual Collection. In: Ridge, M. (Ed.) Crowdsourcing our Cultural Heritage. Farnham: Ashgate, pp. 185-208.

Eynon, R. (2009). Mapping the digital divide in Britain: implications for learning and education. Learning, Media and Technology, 34(4), 277-

290, DOI: $10.1080 / 17439880903345874$.

Eveleigh, A., Jennett , C., Blandford, A., Brohan, P. \& Cox, A. L. (2014). Designing for dabblers and deterring drop-outs in citizen science. ACM Press, pp. 2985-2994. DOI: $10.1145 / 2556288.2557262$.

Fidan, H. (2016). Measurement of the Intersectoral Digital Divide with the Gini Coefficients: Case Study Turkey and Lithuania. Engineering Economics, 27(4), 10.5755/j01.ee.27.4.13882.

Gil-Lacruz, A.L., Marcuello \& C., Saz-Gil, I. (2017). Individual and Social Factors in Volunteering Participation Rates in Europe. Cross-Cultural Research, 51(5), 464-490. DOI: $10.1177 / 1069397117694135$.

Hadley, S. \& Belfiore, E. (2018). Cultural democracy and cultural policy. Cultural Trends, 27(3), 218-223. DOI: 10.1080/09548963.2018.1474009.

Hall, P. (1999). Social capital in Britain. British Journal of Political Science, 29, 417-461.

Haythornthwaite, C. (2009). Crowds and communities: light and heavy work of peer production. In: C. Haythornthwaite and A. Gruzd (Eds), Proceedings of the $42^{\text {nd }}$ Hawaii International Conference on System Sciences. Los Alamitos, CA: IEEE Computer Society. https://www.ideals.illinois.edu/handle/2142/9457.

Holley, R. (2010). Crowdsourcing: How and Why Should Libraries Do It? D-Lib Magazine, 16(3/4). https://doi.org/10.1045/march2010-holley. 
Howe, J. (2006). The Rise of Crowdsourcing. Wired, 16 November 2006.

http://www.wired.com/2006/06/crowds/ (accessed 18 September 2017).

La Regina, A. (2009). L'archeologia e il suo pubblico. Firenze: Giunti.

Lascarides, M. \& Vershbow, B. (2014). What's on the Menu? Crowdsourcing at the New York Public Library. In: M. Ridge (Ed.) Crowdsourcing Our Cultural Heritage. Farnham: Ashgate Publishing Limited, pp. 113-1137.

Li, Y., Savage, M. \& Pickles, A. (2003). Social capital and social exclusion in England and Wales 1972-1999. British Journal of Sociology, 54(4), 497-526. DOI:

10.1080/0007131032000143564.

Lintott, C.J., Schawinski, K., Slosar, A., Land, K., Bamford, S., Thomas, D., Raddick, M.J., Nichol, R.C., Szalay, A., Andreescu, D., Murray, P., \& Vandenberg, J. (2008). Galaxy Zoo: morphologies derived from visual inspection of galaxies from the Sloan Digital Sky Survey. Monthly Notices of the Royal Astronomical Society, 389(3), 1179-1189. DOI: 10.1111/j.13652966.2008.13689.x.

Keinan-Schoonbaert, A., Pett, D., Lombraña González, D. \& Bonacchi, C. (2014). MicroPasts/MicroPasts-Horsfield: The George Horsfield Archive crowdsourcing code base first release (Version 1.0). Zenodo. DOI:10.5281/zenodo.1405468.

Lombraña González, D., Pett, D. \& Bevan, A. (2014). MicroPasts/photomasking: Source code for creation of photomasking in Pybossa (Version 1.0). Zenodo.

DOI:10.5281/zenodo.1405475.

Merriman, N. (1989). Museum visiting as a cultural phenomenon. In: P. Vergo (Ed.) The New Museology. London: Reacktion Books, pp. 149-171.

National Endowment for the Arts (1997). Demographic Characteristics of Arts Attendance. Washington, DC: National Endowment for the Arts, Research Division, Report 71. https://www.arts.gov/publications/demographic-characteristics-arts-attendance-2002 (accessed 23 August 2018).

Neelands, J., Belfiore, E., Firth, C., Hart, N., Perrin, L., Brock, S., \& Woddis, J., (2015). 
Enriching Britain: culture, creativity and growth. Warwick: University of Warwick.

https://warwick.ac.uk/research/warwickcommission/futureculture/finalreport/warwick commis sion report 2015.pdf (accessed 23 August 2018).

Oomen, J. \& Aroyo, L. (2011). Crowdsourcing in the cultural heritage domain: opportunities and challenges. New York, USA: AMC Press, pp.138-149. DOI: 10.1145/2103354.2103373.

Parilla, L. \& Ferriter, M. (2016). Social Media and Crowdsourced Transcription of Historical Materials at the Smithsonian Institution: Methods for Strengthening Community Engagement and Its Tie to Transcription Output. The American Archivist, 79(2), 438-460. DOI: 10.17723/0360-9081-79.2.438.

Pett, D., Lombraña González \& D., Bevan A. (2014). MicroPasts/bronzeAgelndex: Source code for transcription of the NBAI via Pybossa (Version 1.0). Zenodo.

DOI:10.5281/zenodo.1405477.

Ponciano, L. \& Brasileiro, F. (2014). Finding Volunteers' Engagement Profiles in Human Computation for Citizen Science Projects. Human Computation, 1(2), 247-266. DOI: 10.15346/hc.v1i2.12.

Ridge, M. (2013). From Tagging to Theorizing: Deepening Engagement with Cultural Heritage through Crowdsourcing. Curator: The Museum Journal, 56(4), 435-450. DOI: 10.1111/cura.12046.

Ridge, M. (2014). Crowdsourcing Our Cultural Heritage: Introduction. In: M. Ridge (Ed.) Crowdsourcing Our Cultural Heritage. Farnham: Ashgate Publishing Limited, pp. 1-16.

Ridge, M. (2018). Crowdsourcing at the British Library: lessons learnt and future directions. Conference paper, Digital Humanities Congress. https://www.dhi.ac.uk/dhc/2018/paper/148 (accessed 18 August 2018).

Sandell, R. (2002). Museums, Society, Inequality. London and New York: Routledge.

Scifabric (2018). Pybossa. Available from: https://github.com/Scifabric/pybossa (accessed 28 August 2018).

Selwood, S. (2002). Audiences for contemporary art: assertion vs evidence. In: C. Painter 
(Ed.) Contemporary Art and the Home. Oxford: Berg.

Simon, N. (2010). The participatory museum. Santa Cruz, California: Museum 2.0.

Stevenson, D., Balling, G., \& Kann-Rasmussen, N. (2015). Cultural participation in Europe: shared problem or shared problematisation? International Journal of Cultural Policy, 23(1), 89-106. DOI: 10.1080/10286632.2015.1043290.

Taylor, M. (2016). Nonparticipation or different styles of participation? Alternative interpretations from Taking Part. Cultural Trends, 25(3), 169-181. DOI:

10.1080/09548963.2016.1204051.

Terras, M. (2016). Crowdsourcing in the Digital Humanities. In: S. Schreibman, R. Siemens, \& J. Unsworth (Eds.) A new companion to digital humanities. Chichester: John Wiley \& Sons Inc., pp. $420-439$.

Warde, A., Tampubolon, G., Longhurst, B., Ray, K., Savage, M., \& Tomlinson, M. (2003). Trends in social capital: membership of associations in Great Britain, 1991-98. British Journal of Political Science, 33, 515-534. DOI: 10.1017/S000712340321022X.

Wexler, J., Bevan, A., Bonacchi, C., Keinan-Schoonbaert, A., Pett, D., \& Wilkin, N. (2015). Collective Re-Excavation and Lost Media from the Last Century of British Prehistoric Studies. Journal of Contemporary Archaeology, 2(1), 126-142. DOI: 10.1558/jca.v2i1.27124.

Yates, D. (2018). Crowdsourcing Antiquities Crime Fighting: A Review of GlobalXplorer. Advances in Archaeological Practice, 6(2), 173-178. DOI:10.1017/aap.2018.8. 